\title{
Selenium levels and total antioxidant capacity in serum of AIDS adult patients. Preliminary study
}

\author{
M. S. Feliu ${ }^{1}$, A. Squassi ${ }^{2}$, G. Sánchez ${ }^{2}$, A. Piñeiro ${ }^{3}$, K. Vignat ${ }^{3}$, A. C. Mignaqui ${ }^{4}$, E. M. Insani ${ }^{4}$ \\ and N. Slobodianik ${ }^{1}$ \\ ${ }^{1}$ Department of Nutrition, School of Pharmacy and Biochemistry, University of Buenos Aires, ${ }^{2}$ Oral Care Clinic for High \\ Risk Patients (CLAPAR I), School of Dentistry, University of Buenos Aires, ${ }^{3}$ Department of Toxicology, School of Pharmacy \\ and Biochemistry, University of Buenos Aires and ${ }^{4}$ Institute of Food Technology - INTA, Buenos Aires, Argentina
}

Previous results have shown in AIDS children diminished levels of sera selenium ${ }^{(1)}$. Due to the antioxidant effect of this mineral, its deficiency could deteriorate the number of immune cells and/or their function. The aim of this preliminary study is to evaluate selenium status and total antioxidant capacity in a group of AIDS adults. Twenty two patients AIDS between 25 and 50 years old were included. Samples of whole blood were collected from fasting patients. Sera selenium (Se) was determined in haemolysis-free plasma by flame atomic absorption spectrometry; a calibration curve was performed, using commercial standards. Reference values were taken from international bibliography $(60-160 \mu \mathrm{g} / \mathrm{l})^{(2-4)}$. Total antioxidant capacity (TAC) was determined as described by Miller et al. and Re et $a l^{(5,6)}$ and was compared with those obtained on a healthy adult group (mean $=1.92, \mathrm{SD}=0.04$ ). The Ethics Committee of the University of Buenos Aires approved the study. All participants gave informed consent before recruitment. Statistical analyses were performed with the Student's $t$ test.

The results expressed as means (SD) were: Se $(\mu \mathrm{g} / \mathrm{l}) 34.7$ (16.7) and TAC (mM - Trolox equivalents $\left.{ }^{(6)}\right) 1.69(0.18)^{(5,6)}$. When the results were compared with reference values, diminution in their levels were observed $(P<0.01)$. It is important to point out that $81.8 \%$ of the patients presented selenium concentration less than $60 \mu \mathrm{g} / \mathrm{l}$. The same behaviour was observed in other AIDS populations ${ }^{(1,7)}$. A controlled Se supplementation would be necessary to protect immune cells.

This work was supported by University of Buenos Aires (Grant No. B-074).

1. Pallaro A, Barbeito S, Strasnoy I et al. (1998) Acta Bioquim Clin Latinoam XXXII, 555-557.

2. Analytical methods. Flame atomic absorption spectrometry (1989) Varian Australia Pty Ltd. Publication No. 85-100009-00.

3. For analytical methods graphite tube atomizers (1988) Publisher: E. Rothery. Varian Australia Pty Ltd. Publication No. 85-100848-00.

4. Lockitch G, Halstead A \& Wadsworth L (1988) Clin Chem 34, 1625-1627.

5. Miller NJ, Rice-Evans CA, Davies NJ et al. (1993) Clin Sci 84, 407-412.

6. Re R, Pellegrini N, Proteggente A et al. (1999) Free Radic Biol Med 26, 1231-1237.

7. Stambullian M, Feliu MS, López CM et al. (2008) Proc Nutr Soc 67(OCE1), E73 - Online. 